\title{
NUMBER OF EMERGED SEEDLINGS AND SEEDLING LONGEVITY OF THE NON-RECRUITING, CRITICALLY ENDANGERED HÅYUN LÅGU TREE SERIANTHES NELSONII MERR. (FABALES: LEGUMINOSAE) ARE INFLUENCED BY MONTH OF EMERGENCE
}

\author{
Thomas E. Marler ${ }^{1}$ \& April N. Cascasan ${ }^{2}$
}

OPEN ACCESS

${ }_{1,2}^{1,2}$ Isla Paraiso Environmental Consulting, Alstrom Circle, Mangilao, Guam 96923, USA

${ }^{2}$ Present address: Department of Botany, University of Hawaii at Manoa, 3190 Maile Way, Honolulu, Hawaii 96816, USA

${ }^{1}$ thomas.marler@gmail.com (corresponding author), ${ }^{2}$ anjc@hawaii.edu

Abstract: Emergence and longevity of seedlings beneath Guam's only known Håyun Lågu Tree Serianthes nelsonii were studied to determine the fate of every observed seedling during 2013. Newly emerged seedlings were marked with wire stakes every 15 days, then the stakes were collected at each seedling upon death. Longevity of each seedling was calculated from the marked ending and emergence dates. The least number of newly emerged seedlings was recorded at the end of the dry season, and the greatest number of newly emerged seedlings was recorded in the beginning of the rainy season. More than half of the year's 374 seedlings died in less than 30 days. Seedling longevity ranged from a mean of 31 days for seedlings that emerged in May to 78 days for seedlings that emerged in June. Our results reveal that the baseline level of recruitment potential of the lone survivor of this species on Guam is substantial, and underscore the need for further research to determine the factors associated with the acutely limited seedling lifespan.

Keywords: Guam, Janzen-Connell model, Rota, Serianthes nelsonii.
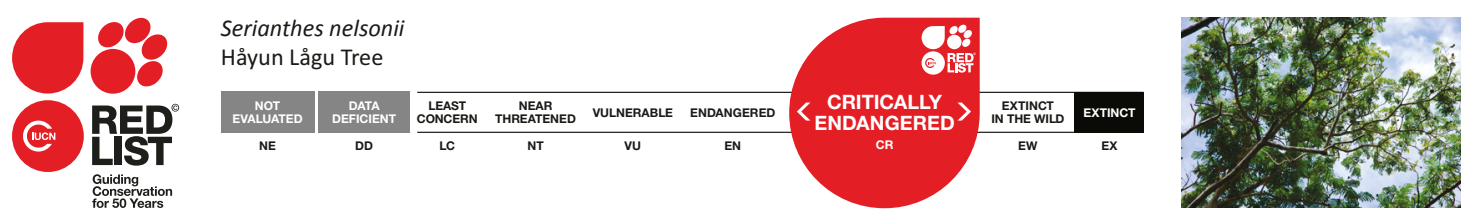

DOI: http://dx.doi.org/10.11609/jott.2100.7.15.8221-8225

Editor: B. Ravi Prasad Rao, Sri Krishnadevaraya University, Anantapuram, India.

Date of publication: 26 December 2015 (online \& print)

Manuscript details: Ms \# 04343 | Received 24 June 2014 | Final received 10 October 2015 | Finally accepted 16 December 2015

Citation: Marler, T.E. \& A.N. Cascasan (2015). Number of emerged seedlings and seedling longevity of the non-recruiting, Critically Endangered Håyun Lågu Tree Serianthes nelsonii Merr. (Fabales: Leguminosae) are influenced by month of emergence. Journal of Threatened Taxa 7(15): 8221-8225; http://dx.doi.org/10.11609/ jott.2100.7.15.8221-8225

Copyright: (C) Marler \& Cascasan 2015. Creative Commons Attribution 4.0 International License. JoTT allows unrestricted use of this article in any medium, reproduction and distribution by providing adequate credit to the authors and the source of publication.

Funding: Support provided through N40192-12-P-5006, administered by the Environmental Flight, Andersen Air Force Base, Guam, USA

Conflict of Interest: The authors declare no competing interests.

Author Details: Thomas E. MARLER is a Professor with the University of Guam. He is a terrestrial ecologist engaged in research and conservation of plants of importance in western Pacific Island nations. APRIL N. CASCASAN is a graduate student with a specialization in ecology, evolution, conservation biology. She is studying evolutionary relationships of endemic Hawaiian Myoporum.

Author Contribution: Development of concepts for experimental methods was shared by both authors, ANC was responsible for all data collection and data entry TEM prepared the first draft of the manuscript. Both authors shared the editing role.

Acknowledgements: Support provided through N40192-12-P-5006, administered by the Environmental Flight, Andersen Air Force Base, Guam, USA.

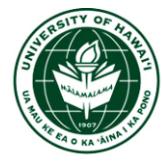

UNIVERSITY O

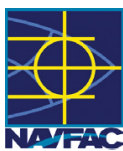




\section{INTRODUCTION}

The Håyun lågu Tree Serianthes nelsonii Merr. is endemic to Rota and Guam Islands within the United States (U.S.) Commonwealth of Mariana Islands and the U.S. Territory of Guam (Fig. 1; Image 1). The tree was reported as extremely rare when it was first described (Merrill 1919). The natural population on Guam has been reduced to one known mature tree (Wiles et al. 1996). The species is listed as endangered by the U.S. Endangered Species Act (US Fish and Wildlife Service 1987) and as Critically Endangered in the IUCN Red List (Wiles 1998). Lack of natural regeneration is considered the major cause of population decline.

A recovery plan was published in 1994 (U.S. Fish and Wildlife Service, 1994), and called for research into the factors that are limiting the natural recruitment. Predation by wild ungulates was considered one of the major threats to seedlings in the past (U.S. Fish and Wildlife Service 1994; Wiles et al. 1996). A functioning exclusion fence surrounding Guam's only mature tree was repaired in October 2012 and has been maintained since that date. All exotic plant species were removed from the exclosure by December 2012. These endeavors enabled the potential to monitor seedling emergence, health, and longevity in the absence of alien plant competition and introduced ungulate pressure.

Our objectives were to evaluate the early dynamics of seedling performance beneath Guam's only $S$. nelsonii tree. The results will provide the foundation to begin understanding limitations to recruitment, which will address several of the recovery actions listed in the U.S. Fish and Wildlife Recovery Plan for S. nelsonii (U.S. Fish and Wildlife Service 1994).

\section{MATERIALS AND METHODS}

This research was conducted under United States Endangered Species Act Recovery Permit TE-84876A-0. The sole known surviving $S$. nelsonii tree on Guam was visited twice monthly beginning 15 November 2012 and continuing for 16 months. During each visit, every seedling that had emerged since the most recent visit was marked with a wire stake and the date was recorded (Image 2). In addition, every pre-existing wire stake that did not have a live seedling associated with it was collected and recorded as the date of death. Longevity of each seedling associated with each stake was calculated as the stake collection date minus the recorded emergence date.

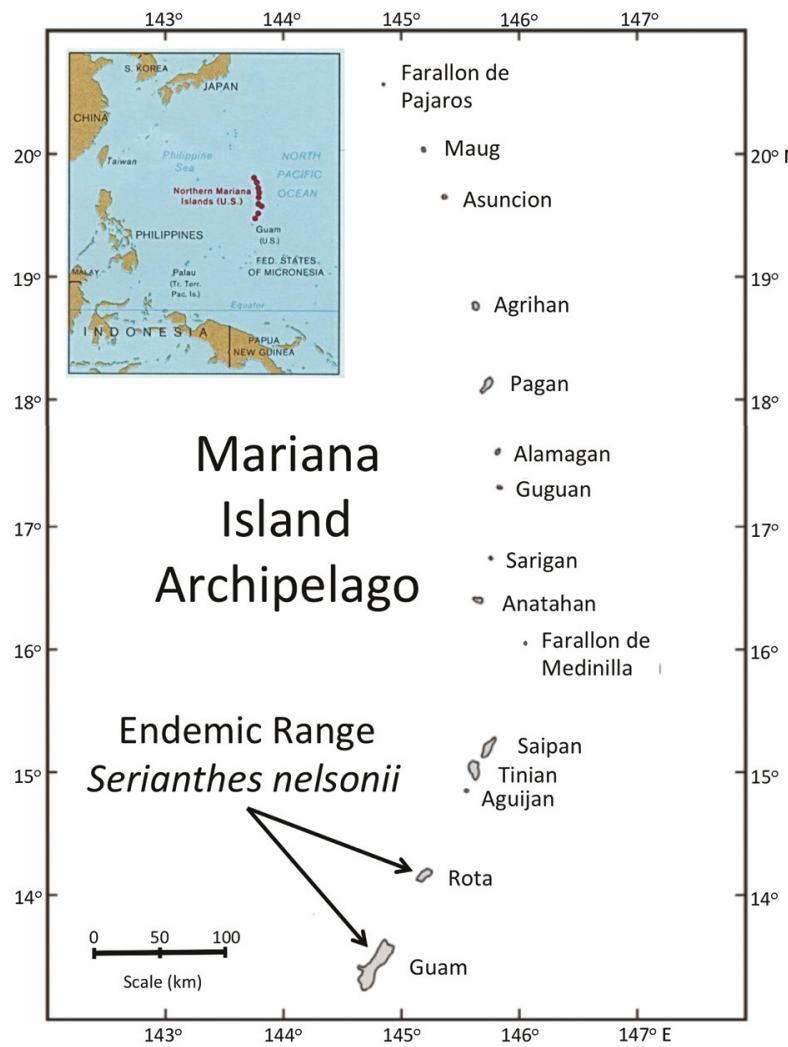

Figure 1. The Mariana Island Archipelago is comprised of the United States Commonwealth of the northern Mariana Islands and the United States Territory of Guam. The endemic range of Serianthes nelsonii is restricted to the islands of Guam and Rota.

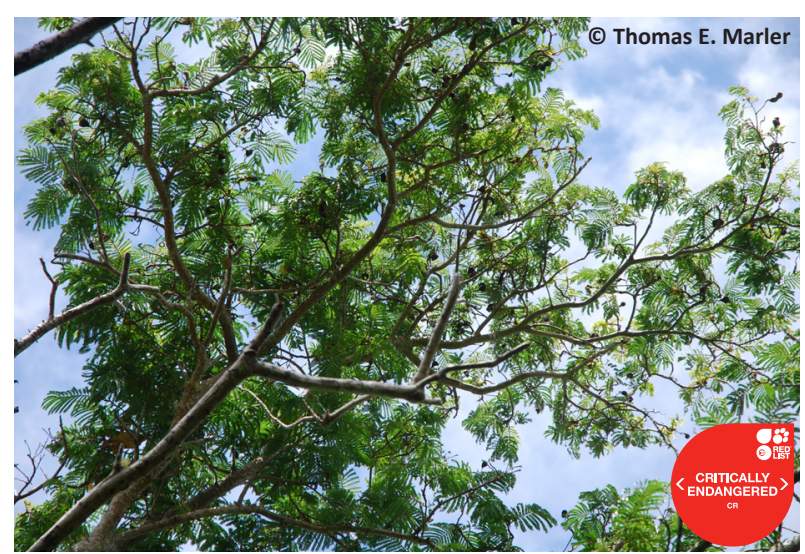

Image 1. The canopy of a mature Serianthes nelsonii tree exhibits fine-textured foliage and retained dried fruits.

For the purpose of this report, we included every seedling that emerged during 2013 in order to quantify recruitment potential, define issues related to seedling longevity, and consider potential causes of mortality. In order to follow the mortality of every seedling that emerged through December, the site visits continued through 23 March 2014 . The emergence 


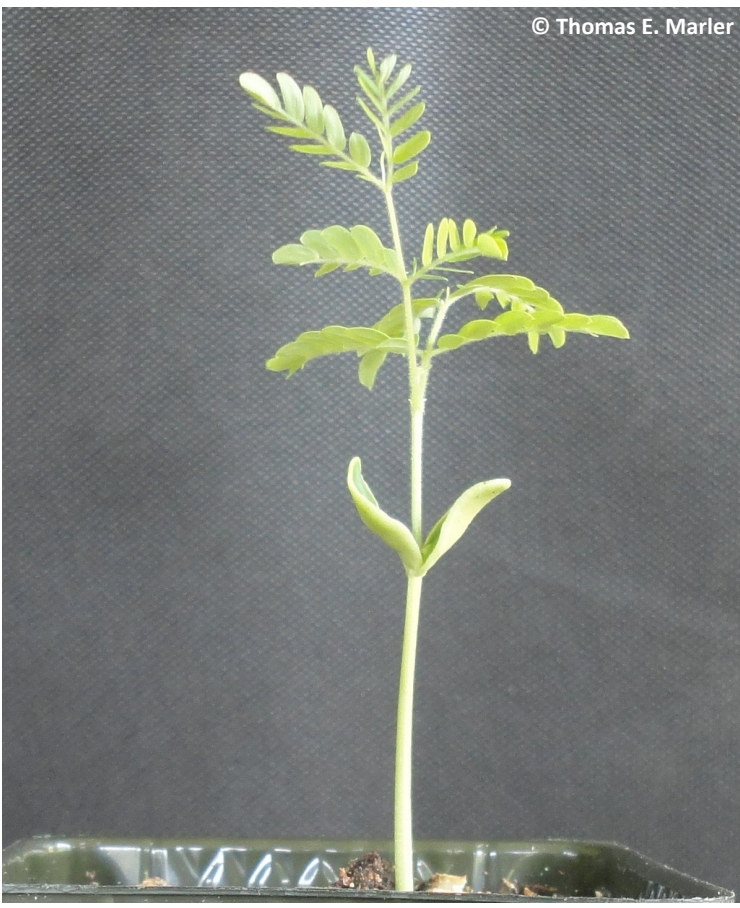

Image 2. A week-old Serianthes nelsonii seedling has retained cotyledons and one pair of true leaves.

data and the longevity data were sorted by month and discussed in relation to seasonal rainfall patterns.

\section{RESULTS}

The emergence of 374 seedlings was recorded during 2013. Almost $30 \%$ of the seedlings died in less than 15 days, $51 \%$ died in less than one month, and $76 \%$ died in less than two months (Fig. 2). Only $10 \%$ of the seedlings lived longer than three months.

Seasonal patterns of seedling emergence revealed highly contrasting numbers for each of the 12 months (Fig. 3). The monthly mean was 31 new seedlings, and the differences among the months were more than tenfold. The range was from five new seedlings in March to 59 new seedlings in November.

Longevity of the newly emerged seedlings was also contrasting among the months of emergence (Fig. 4). The variation in longevity was not as great among the months as was the number of newly emerged seedlings, and ranged from 31 days for seedlings that emerged in May to 78 days for seedlings that emerged in June. Only three of the 2013 seedlings lived for more than 200 days, and these emerged in early March, mid June, and mid July.

The first quarter of the year represents the first

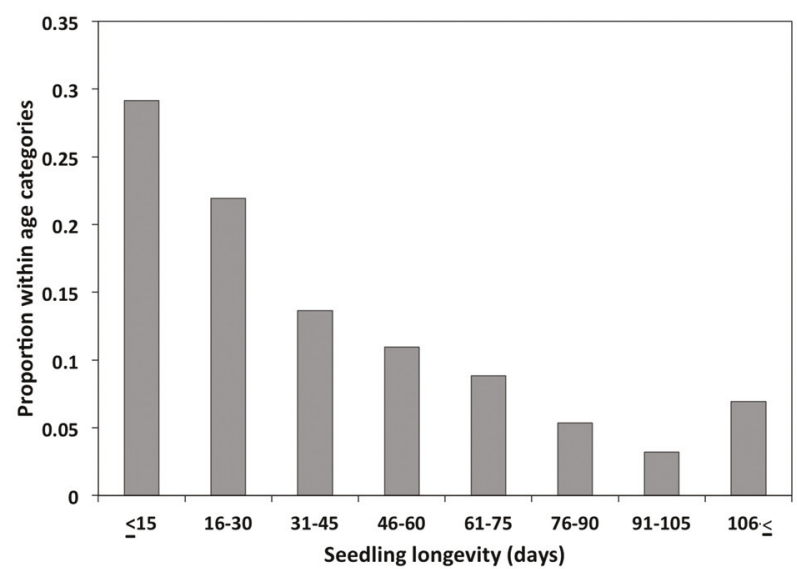

Figure 2. The proportion of the 374 Serianthes nelsonii seedlings that emerged in 2013 within 15-day age interval categories.

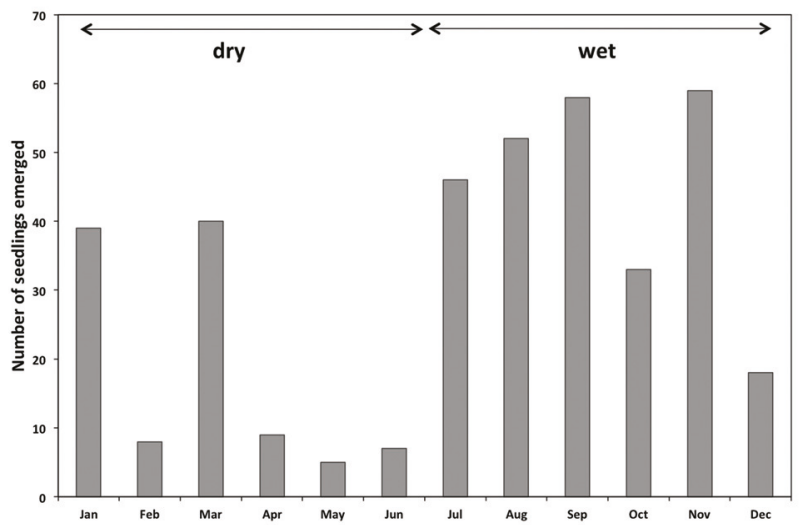

Figure 3. The number of Serianthes nelsonii seedlings that emerged in 2013 for each month. Dry and wet refer to major annual seasons.

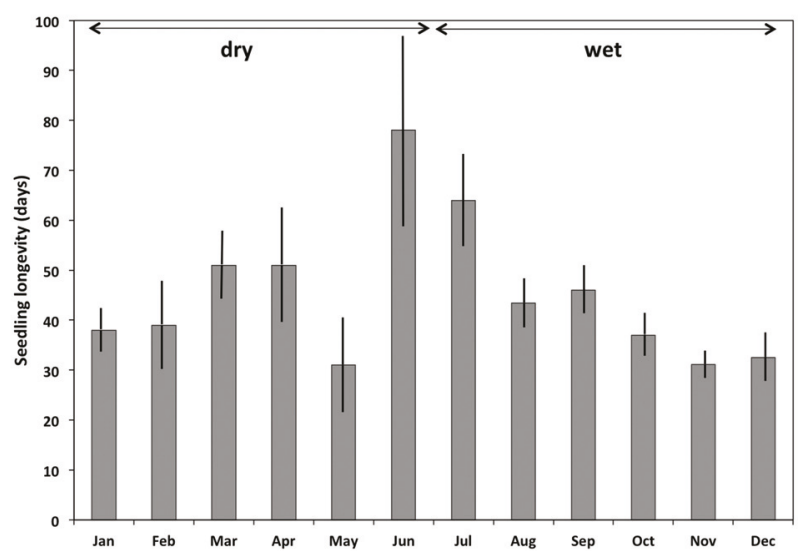

Figure 4. Mean longevity of the 374 Serianthes nelsonii seedlings that emerged in 2013 as a function of month. Dry and wet refer to major annual seasons. Mean \pm SE. 
half of the annual dry season, and $29 \pm 10$ (mean \pm SE) seedlings emerged per month and exhibited a mean longevity of $43 \pm 4$ days. The second quarter of the year represents the second half of the annual dry season, and $7 \pm 1$ seedlings emerged per month and exhibited a mean longevity of $53 \pm 14$ days. The third quarter represents the first half of the annual rainy season, and $52 \pm 4$ seedlings emerged per month and exhibited a mean longevity of $51 \pm 7$ days. The fourth quarter is the second half of the annual rainy season, and $37 \pm 12$ seedlings emerged per month and exhibited a mean longevity of $34 \pm 2$ days.

\section{DISCUSSION}

Proposed actions for recovery of $S$. nelsonii as described in the published recovery plan (U.S. Fish \& Wildlife Service 1994) represent the only attempt to date to recover an endangered plant in Micronesia (Wiles et al. 1996). Yet little has been done in the past 21 years to fulfill the goals within that formal recovery plan. For example, frequent site visits on a fixed schedule are required to determine limitations to $S$. nelsonii recruitment, but were never employed in past studies. Most historical site visits have revealed the presence of a healthy number of seedlings (e.g., Wiles et al. 1996; Marler \& Musser 2015), but there was no way of determining if the stand of seedlings was comprised of recently emerged seedlings of limited age or older but persistent seedlings with constrained growth. We have now shown that Guam's only known mature tree exhibits sustained high recruitment potential with more than one seedling emerging on average per day throughout 2013 , and $100 \%$ recruitment failure with extremely short lifespan for all seedlings. Therefore, the turnover rate of the in situ group of seedlings is considerable.

The thanatological aspects of studying $S$. nelsonii germination and seedling establishment cannot be avoided given our current level of knowledge. First, a portion of the seeds appears to be programmed for death. Based on our in situ and nursery observations, some of these germinate but never emerge, while others emerge then immediately begin to decline in health. For this portion of potential recruits, nothing we have observed in situ and nothing we have provided in a nursery setting has been effective in turning off the impending mortality. We have discussed the possibility of inbreeding depression as a cause of this behavior (Marler et al. 2015), but declining health due to the tree's age or other physiological traits may also be involved. Second, healthy seedlings that remain persistent after the initial pulse of mortality also exhibit relatively short lifespan. Ungulate damage, arthropod herbivory, and soil-borne pathogens have been proposed as causal for the extensive seedling mortality (U.S. Fish and Wildlife Service 1994; Wiles et al. 1996; Marler \& Musser 2015).

If we juxtapose each month of seedling emergence onto the seasonal trends in rainfall patterns, the results may provide some understanding of the annual $S$. nelsonii seedling population behavior. The quarter exhibiting the least number of new seedlings was the second half of the dry season from April to June, when only $6 \%$ of the annual emergences occurred. The quarter exhibiting the greatest number of new seedlings was the first half of the rainy season from July to September, when $42 \%$ of the annual emergences occurred. Rainfall patterns indicated $11 \%$ of the annual rainfall occurred in the second half of the dry season, and $42 \%$ of the annual rainfall occurred in the first half of the rainy season. Serianthes nelsonii seeds exhibit physical dormancy (Finch-Savage \& Leubner-Metzger 2006), where the intact seed coat physically inhibits the factors that enable germination such as imbibition of water and leaching of inhibitory substances. In order to break this form of dormancy in the seed bank, each seed coat must be broken down by biotic and abiotic factors over time. The rainfall and emergence patterns that we recorded fit well with the scenario where high rainfall in the current month combines with breakdown of the physical dormancy in the previous months to define total numbers of seedling emergence. Seeds that pass through the breakdown of physical dormancy during the rainy season may germinate immediately. However, seeds that pass through the breakdown of physical dormancy during the dry season may exhibit non-dormant conditions but wait until sufficient rainfall occurs before proceeding to germinate. Therefore, the initial high rainfall events in the first half of the rainy season may stimulate germination of the cumulative number of seeds that were able to pass through the conditions of dormancy throughout the previous dry season months.

Comparing seasonal trends in seedling longevity and rainfall may also reveal potential causes of variation in longevity. For example, decreased longevity in the dry season may indicate that one of the main seasonal drivers of mortality may be drought stress of newly emerged seedlings due to limited root size in the litter layer. Alternatively, if seedling longevity is greater in the dry season, the mortality may be pathogen-related, as root pathogens are usually less severe in dry conditions. Moreover, ambient light load is greater in Guam's dry 
season because of more clear days, so greater longevity in the dry season may indicate light limitation in the rainy season is partly causal of the short lifespan of S. nelsonii seedlings. Our results indicated the two months exhibiting seedling longevity much greater than the annual mean were June and July. The months subsequent to emergence of these seedlings fell within the rainy season, indicating increased water availability may be at least one of the drivers of increased seedling longevity when seasonal aspects are considered.

The three seedlings that lived more than 200 days exhibited extraordinary longevity in relation to the population mean. These seedlings emerged in March, June, and July. This span in emergence dates did not allow the seasonal rainfall patterns to be used to identify possible causes for why these three outliers were able to better cope with the biotic or abiotic factors that limit $S$. nelsonii seedling lifespan.

Our methods were highly informative, but the temporal resolution of 15-day intervals between site visits potentially under-estimated total seedling emergence throughout 2013. These methods accurately quantified every seedling that lived at least 15 days. However, our methods did not allow us to determine if any seedlings emerged and died in less than 15 days. Therefore, we do not know the low end of seedling longevity or the true number of 2013 seedlings inclusive of all seedlings that died in less than 15 days. This limitation to our temporal scale may have underestimated the $<15$-day category. More frequent site visits would be required to quantify the number of seedlings that emerge and die in less than 15 days.

All observations to date indicate that the framework of the Janzen-Connell model (Connell 1971; Janzen 1970; Clark \& Clark 1984) may be useful for design of experimental methods to more fully understand various causal mechanisms of the acutely limited $S$. nelsonii seedling lifespan. No seed dispersers are known, so the study of natural seedling behavior and longevity at locations away from the maternal tree are not possible. However, the model calls on threats such as host-specific seed predators, seedling herbivores and pathogens, and intra-specific competition for resources to explain why progeny close to the maternal parent may exhibit limited lifespan. Experimental methods may be used for mitigation of these various abiotic and biotic threats for a portion of newly emerging seedlings (Marler \& Musser 2015), and these methods may uncover which of the threats cause such rapid mortality beneath the maternal tree.

Five actions were outlined in the Recovery Plan for Serianthes nelsonii: secure habitat and manage threats of current populations, conduct research, augment current populations, reestablish in former range, and validate recovery objectives (U.S. Fish and Wildlife Service 1994). Our results are useful for improved management of the threats to the current populations and advancing research into limiting factors. Therefore, we have addressed two of the five published actions with this study.

\section{REFERENCES}

Clark, D.A. \& D.B. Clark (1984). Spacing dynamics of a tropical rain forest tree: evaluation of the Janzen-Connell model. American Naturalist 124: 769-788; http://dx.doi.org/10.1086/284316

Connell, J.H. (1971). On the role of natural enemies in preventing competitive exclusion in some marine animals and in rain forest trees, pp. 298-312. In: den Boer, P.J. \& G.R. Gradwell (eds.). Dynamics of Populations. Centre for Agricultural Publishing and Documentation, Wageningen, Netherlands.

Finch-Savage, W.E. \& G. Leubner-Metzger (2006). Seed dormancy and the control of germination. New Phytologist 171: 501-523; http:// dx.doi.org/10.1111/j.1469-8137.2006.01787.x

Janzen, D.H. (1970). Herbivores and the number of tree species in tropical forests. American Naturalist 104: 501-529; http://dx.doi. org/10.1086/282687

Marler, T.E., A.N. Cascasan \& J.H. Lawrence (2015). Threatened native trees in Guam: short-term seed storage and shade conditions influence emergence and growth of seedlings. Hort Science 50: 1049-1054.

Marler, T. \& C. Musser (2015). Potential stressors leading to seedling mortality in the endemic Håyun lågu tree (Serianthes nelsonii Merr.) in the island of Guam. Tropical Conservation Science 8: 738-744.

Merrill, E.D. (1919). Additions to the flora of Guam. Philippine Journal of Science 15: 539-544.

U.S. Fish and Wildlife Service (1987). Determination of endangered status for Serianthes nelsonii Merr. (Hayun lagu or Tronkon Guafi). Federal Register 52(32): 4907-4910.

U.S. Fish and Wildlife Service (1994). Recovery plan for Serianthes nelsonii. U.S. Fish and Wildlife Service, Portland, O Oregon. 60 pages. Available online at <http://www.fws.gov/pacificislands/ recoveryplans.html>. Downloaded on 30.ix.2015.

Wiles, G. (1998). Serianthes nelsonii. The IUCN Red List of Threatened Species. Version 2015.1. <www.iucnredlist.org>. Downloaded on 30 November 2015; e.T30437A9550169; http://dx.doi.org/10.2305/ IUCN.UK.1998.RLTS.T30437A9550169.en

Wiles, G.J., I.H. Schreiner, D. Nafus, L.K. Jurgensen \& J.C. Manglona (1996). The status, biology, and conservation of Serianthes nelsonii (Fabaceae), an endangered Micronesian tree. Biological Conservation 76: 229-239; http://dx.doi.org/10.1016/00063207(95)00078-x 